DOI: 10.17805/trudy.2015.4.11

\title{
МАССОВОЕ ПРОИЗВОДСТВО СИМВОЛИЧЕСКОЙ ПРОДУКЦИИ: СТРАТЕГИИ ПРИСВАИВАНИЯ
}

\author{
А. Р. Кожаринова \\ (Московский гуманитарный университет)
}

Аннотация: В статье анализируется специфика формирования рынка массовой символической продукции в культуре постмодерна и определяются стратегии его производства, важной из которых является присваивание достижений высокой культуры.

Ключевые слова: символическая продукция, массовое производство, современная культура, культурный капитал

\section{MASS PRODUCTION OF SYMBOLIC PRODUCT: STRATEGIES OF APPROPRIATION}

\author{
A. R. Kozharinova \\ (Moscow University for the Humanities)
}

Abstract: The article analyzes the emergence of the mass market for symbolic product in postmodern culture, with a focus on the strategies of such production. An important strategy discussed in detail in the article is appropriation the achievements of high culture.

Keywords: symbolic product, mass production, contemporary culture, cultural capital.

Проблематикой функционирования современных медиа занимаются исследователи, принадлежащие разнообразным сферам гуманитарного знания. При определенном различии в расстановке акцентов, ученые сходятся во мнении о важности анализа медиа для исследования феномена массовой культуры и его тиражирования.

В последние десятилетия исследовательская оптика все в большей степени фокусируется на изучении процессов культурной динамики, что объясняется попыткой экстраполяции уже изученных современных закономерностей для прогнозирования будущей ситуации. Так П. Бурдье в работе «Рынок символической продукции», анализируя динамику интеллектуальной и художественной культуры, приходит к выводу, что с определенного момента история культуры начинает развиваться как исто- 
рия становления институций, производящих символическую продукцию (Бурдье, 1994). Такой реперной точкой становится эпоха Возрождения, ведь именно в этот период происходит процесс автономизации интеллектуальной и художественной культуры. Причиной подобной бифуркации, с одной стороны, становится появление в эту культурную эпоху социально диверсифицированного слоя потребителей, с другой стороны - еще более диверсифицированного корпуса производителей и продавцов символических благ, освобожденных от внешней цензуры: моральной, эстетической и церковной. Появляющиеся в это время первые в истории институции по потреблению и распространению символических благ (издательства, салоны, академии, дирекции театров) становились инстанциями легитимации культуры. Эти процессы явились подготовительными для становления в XIX в. культурной индустрии, предлагающей расширяющемуся кругу публики новые формы - мелодраму, водевиль, оперетту, бульварную литературу, фельетон, что привело к окончательному становлению рынка символических благ. Искусство перестало предназначаться исключительно для бескорыстного символического присвоения, а стало товаром, циркуляция которого в обществе подчинена экономическим законам спроса и предложения.

В целом, в своей общесоциологической теории французский постструктуралист П. Бурдье выделяет объективно существующие подпространственные структуры - социальные поля, к которым относится культура, экономика, политика, религия, собственно медиа и т. д. Особо исследователь выделяет так называемые «поля производства и обращения символических благ» (там же). Исследователь делит поля символических благ на «ограниченные», предназначенные, пусть даже на короткий срок, для круга производителей, и «массовые», предназначенные для непроизводителей - масс. Взаимная центробежность, оппозиционность (если не сказать враждебность) этих полей, их стремление к автономизации вполне естественны.

Поле массового производства, по П. Бурдье, характеризуется зависимостью от внешних требований, поскольку положение производителей культуры подчинено держателям инструментов рыночного производства и конкурентного распространения. Производимое в рамках массового поля искусство является недифференцированным посланием, характеризующимся использованием общедоступных и испытанных технических приемов, стереотипизированностью, отказом от неоднозначно трактующихся тем, социальным консерватизмом, что обуславливается ориентацией этого поля на расширение круга своих потребителей. П.Бурдье сосредотачивает свое внимание на рассмотрении важнейшего из всех массовый полей - медийного, которое он анализирует на примере поля 
телевидения и поля журналистики (Бурдье, 2002). Внешнее давление на эти поля особенно ощущается. Помимо вердикта рынка, выраженного в присвоении некомпетентными массами рейтингов или поддержании ими же уровня продаж, на работников медиа действует мощный политический или экономический прессинг. Причем если первый вид давления осуществляется относительно открыто по отношению к производителю медиатекстов, то экономический прессинг анонимен, следовательно, ему невозможно открыто сопротивляться.

Главным социальным фактором, детерминирующим практику производства внутри каждого из полей, является «иерархическая позиция каждого жанра, дисциплины, специальности (которая управляет системой механизмов ориентации и селекции), а также позиция различных производителей в иерархии» (Бурдье, 1994: 55). Эти иерархические позиции должны быть вписаны в логику интеллектуальной траектории и иметь своей целью обеспечение «лучшей экономической или символической рентабельности определенного вида культурного капитала» (там же). Стратегия конституирования иерархических позиций осуществляется через завоевание легитимности производства, воспроизводства и обращения культурных благ. Символическая продукция медиа должна быть признана как среди коллег, профессионалов, экспертов, так и среди публики. Признание позволяет держателям и производителем медиа стать обладателями значительного символического капитала и дает возможность навязывать благоприятные для себя приемы культурного производства антагонистическому полю. Основной ставкой в конкурентной борьбе является «символическая власть», осуществляющая «легитимное насилие», в данном контексте понимаемое как монополизация структур распределения специфического культурно-символического капитала. Авторитетность символического капитала может ратифицироваться как его узнаваемостью и цитируемостью, так и через доступное монопольным властным структурам официальное ранжирование культурных производителей посредством присуждения им званий, премий, дипломов, а самое главное - прав на дешифровку и интерпретацию всего, находящегося в культурном поле, что является легитимным насилием со стороны властных структур. Разумеется, легитимация того или иного культурного поля значительно повышает его конкурентоспособность.

Вполне понятно, что победители в конкурентной борьбе склоняются к стратегиям защиты своего культурного поля. Стратегии защиты можно разделить на два вида: ортодоксальные и еретические. Последние противостоят первым, в них могут включаться собственники меньшего символического капитала - к примеру, азартные новички, креативная молодежь, словом «творческое меньшинство» (А. Тойнби). В современной 
российской массовой культуре борьба между ортодоксами и их противниками наглядно иллюстрируется неравенством доступа «еретических» медиа-персон к выступлениям на федеральных телеканалах и их попытками «прорваться» к массовой аудитории на каналах региональных, спутниковых или кабельных.

Для понимания функционирования современной массовой культуры представляется важным остановиться на подробном анализе отношений между полем ограниченного производства и полем массового производства. Подобно тому, как в китайских швейных мастерских по незаконно используемым лекалам, построенным кутюрье из домов Высокой моды, шьются подделки, массовая культура лавирует, по меткому выражению П. Бурдье, «между плагиатом и пародией». Перенесенное из ограниченного поля науки специализированное знание в поле массового производства меняет свою природу, утрачивает основания, ухудшает характеристики. Такое перемещенное знание становится нетождественным своему изготовленному в другом (научном) поле источнику, хотя на нем вроде бы даже и стоит «фирменная» опознавательная метка. Подобно тому, как хозяин подпольной швейной мастерской похищает идеи свободных креативных производителей из мира «высокой» моды, функционирующей по рыночным законам, масскульт присваивает созданные ими смыслы, произведенные в элитарных полях, извлекая из этого акта присвоения коммерческую выгоду. Потребляющую полученный продукт массу не смущает имитационность подделки, а, следовательно, массовая культура вновь и вновь, как к донору, обращается к «высокой» культуре, что обеспечивает ориентированному на коммерческую логику масскульту столь необходимый эффект новизны.

Подобная стратегия присвоения-заимствования символической продукции усиливается в современную эпоху, когда попытки подобного межкультурного диалога не только встречаются все чаще, становятся все более явными, но и легитимируются интеллектуалами, буквально подталкивающими производителей антагонистических полей символического производства к стратегиям заимствования-присвоения. Первым к снятию оппозиции между полями символического производства призвал Л. Фидлер, опубликовавший в журнале «Плейбой» (что показательно) статью «Пересекайте границы, засыпайте рвы». В ней автор рассуждал о необходимости стирания границ между массовой и элитарной литературой и убеждал, что следствием снятия границ между культурными полями станет расширение их возможностей и обретение ими дополнительной свободы (см.: Фидлер, 1993). Создатели культурных текстов, по мнению Л. Фидлера, должны были стать «двойными агентами», профессионально работающими на оба «фронта» - элитарный и массовый . Идеи Л. Фидле- 
ра были поддержаны архитектором и теоретиком искусства Ч. Дженксом, который также призвал авторов к смысловому «двойному кодированию» (Дженкс, 1985). Необходимость синтетического пути «засыпания рвов» отстаивала известная английская писательница А. Мердок, выделявшая два равноправных и равноценных для аудитории типа романа: «журналистский» (т.е. массовый) и «кристаллический» (элитарный) (см.: Бак, 1992). Окончательно идеи о снятии оппозиции между массовой и элитарной культурой оформились в постмодернистской философии в работах Ж. Делеза, Ф. Гваттари, Ж. Деррида, У. Эко, Р. Барта, М. Фуко.

Таким образом, стратегией создателей «массового» поля производства символической продукции является присваивание интеллектуальной, фабулятивной, эстетической или какой-либо иной специфики, произведенной в полях ограниченного производства культурных текстов посредством цитирований, экзотических коллажей, пастишей, метаповествований и т. п. Наследие высокой культуры «деконструируется» (Ж. Деррида), прививается, а иногда и укореняется в поле массового производства. При этом обновления контента «массового» поля символической продукции производятся осторожно и постепенно: в условиях экономической конкуренции необходимо избегать их чрезмерной интеллектуальной сложности и эстетической экстравагантности, способных вызвать непонимание или раздражение потребителей и, как следствие, опасный с точки зрения рыночной ориентации массовой культуры разрыв в коммуникации.

\section{СПИСОК ЛИТЕРАТУРЫ}

Бак, Д. П. (1992) История и теория литературного самосознания: творческая рефлексия в литературном произведении. Кемерово : КемГУ. 82 с.

Бурдье, П. (1994) Рынок символической продукции // Вопросы социологии. № 5 . С. 50-61.

Бурдье, П. (2002) О телевидении и журналистике. М. : Фонд научных исследований «Прагматика культуры» ; Институт экспериментальной социологии. 160 с.

Дженкс, Ч. (1985) Язык архитектуры постмодернизма. М. : Стройиздат. 138 с.

Фидлер, Л. (1993) Пересекайте рвы, засыпайте границы // Современная западная культурология: самоубийство дискурса. М. : Мысль. 540 с. С. $462-518$. 
Кожаринова Анна Ростиславовна - кандидат философских наук доцент кафедры философии, культурологии и политологии Московского гуманитарного университета. Адрес: 111395, Россия, г. Москва, ул. Юности, д. 5. Тел.: +7 (499) 374-61-81. Эл. адрес: anna_adv@inbox.ru

Kozharinova Anna Rostislavovna, Candidate of Philosophy, Associate Professor, Department of Philosophy, Culturology and Politology, Moscow University for the Humanities. Postal address: 5 Yunosti St., 111395 Moscow, Russian Federation.Tel.: +7 (499) 374-61-81. Email: anna_adv@inbox.ru 